\title{
Antiphospholipid Syndrome may Lead to Softtissue Defect Requiring Reconstruction
}

\section{Yusuf Kenan Coban*}

Medical Faculty, Inonu University, Malatya, Turkey

Antiphospholipid syndrome (APS) manifests as systemic thrombotic disorders including recurrent deep vein thrombosis, pulmonary thromboembolism, brain stroke and fetal loss in the presence of antiphospholipid antibodies. The syndrome can be secondary to many causes including systemic lupus erythematosus or pulmonary antiphospholipid syndrome. The many etio pathogenic mechanisms involved generally act together so that it is difficult to say which is the main cause, especially in elderly patients.

Systemic lupus erythematosus (SLE) is an auto immune disease of unknown origin affecting virtually all organ systems. Beyond genetic and environmental factors, cytokine imbalances contribute to immune dysfunction, trigger inflammation, and induce organ damage. Patients with the APS who do not have SLE are considered to have the primary antiphospholipid antibody syndrome; patients with SLE who also have both antiphospholipid antibodies and relevant clinical events are considered to have the secondary antiphospholipid antibody syndrome. The evolution depends mainly on the multi-organ involvement and how early immuno suppressive and/or anticoagulant treatment is started. We present a case with SLE who had soft tissue defect requiring reconstruction in this report.

\section{Case report}

The patient was 39 years-old female and had a recent high dose corticosteriod treatment for her active disease. Her past medical history showed that she was diagnosed as having SLE 10 years earlier. SLE was diagnosed on the basis of its clinical manifestations and the demonstration of characteristic anti-nuclear antibodies. The first manifestation of the disease was started with 2 episodes of skin rash that was erythematous, non blanching presented at an interval of 10 months. Symmetrical weakness of proximal muscle and elevation of serum muscle enzymes (serum aldolase) were detected at that time. During both episodes, the treating consultant found thrombo cytopenia and the first episode was treated within travenous gamma globulin, and during these condepisode, the patient was started on oral prednisolone $2 \mathrm{mg} /(\mathrm{kg}$ day), which continued till the age of 34years. After this, the patient had an uneventful period of 1 year; again after 1 year, th epatient presented with similar complaints described above. Further investigations were done that showed thrombocytopenia, muscle creatine kinase marginally raised, normal electromyogram, normal liver function test, and serum aldolase within the normal range

Last active disease period was begun 5 months earlier. She had fatigue, fever, weightloss, skinrash, arthritis or arthralgias. Treatment was initiated with injection methyl prednisolone (MP) $1 \mathrm{gm}$ IV 3 days followed by oral prednisolone $1 \mathrm{mg} / \mathrm{kg}$ body weight. The patient responded promptly with gradual amelioration of all clinical findings within the ensuing 10 days. Investigation at this time revealed $\mathrm{Hb} 9.9$ $\mathrm{gm} / \mathrm{dl}$, normochromic normocytic RBCs, reticulocyte count $1.5 \%$, total leucocyte count $5700 / \mathrm{mm} 3$ (polymorphs $77 \%$, lymphocyte $25 \%$ ), MCV 90.2, MCH 29.6, MCHC 30.8, platelet count of 90,000/dl, urea $21 \mathrm{mg} /$ $\mathrm{dl}$, Cr $0.7 \mathrm{mg} / \mathrm{dl}$, uricacid $3.6 \mathrm{mg} / \mathrm{dl}, \mathrm{Na} 137 \mathrm{meq} / \mathrm{l}$, and K $4.4 \mathrm{meq} / \mathrm{l}$. Liver and thyroid function tests, serum urea, creatinine were normal. Laboratory criteria were positive titers of lupus anticoagulant antibody
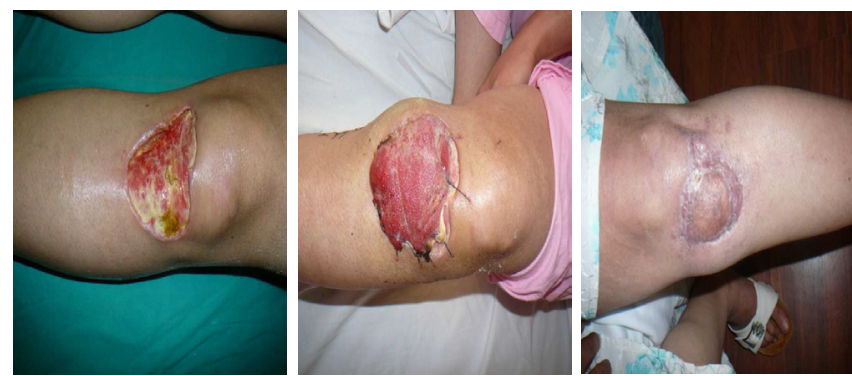

Figure 1:

a) A pre tibial defect occurred during the management of the disease.

b) Medial based hemi gastrocnemius flap transfer to the defect.

c) Complete healing of the wound.

moderate to high titers of anti cardiolipin Ig M(45MPL UI/ml) and moderate titers of Beta2-glycoprotein. The 24-h urinary protein excretion rate was $178 \mathrm{mg}$. Ultra sonography of the abdomen was within normal limits without any apparent pelvic/ovarianmass. Gynecological examination and Papanicolaousmear of the cervical region was normal. Mammography was within normal limits. Activsated partial thromboplastin time, anti-phospholipid antibodyIgM (aPL) were within normal limits. At the end of treatment process, there was a skin gangrene over her left pretibialarea. Previous skin biopsy of the same lower limb skin showed the thrombotic vasculopathy with no evidence of vasculitis. The cyanotic areas progressed to gangrene. Then, she was referred to PlasticSurgery for her pre tibial wound. The wound exposing tibial was $7 \times 10 \mathrm{~cm}$ in diameter. The defect was reconstructed with a hemi gastrocnemius flap and full thickness skin graft and a unevenfull healing was achieved (Figure 1a-c). During the wound healing period there was no wound healing delay or systemic activation of disease.

\section{Discussion}

APS is the most common acquired thrombophilia, characteristic clinical manifestations are heterogenous with venous and arterial thrombosis. Diagnosis is made through the association of clinical and labaratory criteria. The clinical criteria are thrombosis or history of obstetrical morbidity. Acceptable tests for lupus anticoagulant include the dilute activated partial thromboplastin time test, the kaolin clotting time test, or the Russell viper venom time test. Positive laboratory

*Corresponding author: Yusuf Kenan Coban, Medical Faculty, Inonu University, Malatya, Turkey, E-mail: ykenanc@yahoo.com

Received November 29, 2011; Accepted February 29, 2012; Published March 02, 2012

Citation: Coban YK (2012) Antiphospholipid Syndrome may Lead to Softtissue Defect Requiring Reconstruction. Anaplastology 1:102. doi: 10.4172/21611173.1000102

Copyright: (c) 2012 Coban YK. This is an open-access article distributed unde the terms of the Creative Commons Attribution License, which permits unrestricted use, distribution, and reproduction in any medium, provided the original author and source are credited. 
Citation: Coban YK (2012) Antiphospholipid Syndrome may Lead to Softtissue Defect Requiring Reconstruction. Anaplastology 1:102. doi: 10.4172/2161-1173.1000102

tests in clinically well persons do not justify either diagnosis of the APS or prophylactic treatment, but they do justify re examination and monitoring of the patient. There are striking inconsistencies among commercial laboratories doing antiphospholipid antibody assays [1]. Because antinuclear and anti-DNA antibodies occasionally occur in patients with the primary APS, clinical criteria for both the primary APS and SLE must be present for both diagnoses to be made [2,3]. In the secondary APS, manifestations of the primary antiphospholipid antibody syndrome adversely affect survival [4]. Some patients with SLE have transiently present (usually low-titer) antiphospholipid antibody that varies with disease activity. These patients, in contrast to those with sustained high-titer antibody, generally do not have complications of the APS [5]. In our case there was also high titers of antiphospholipid antibody and there was no internal organ invovlment. Patients with positive "lupus anticoagulant" tests but normal results on activated partial thromboplastin time or Russellvipervenom time tests generally have normal ELISA results for anticardiolipin antibody. The isolated "lupusanticoagulant" is thus of unknown significance. Catastrophic APS occurs in 1\% of APS patients and associated with a mortality rate upto $50 \%$ [6]. In these sub group there are usually evidences of disseminated intravascular coagulopathy and micro angiopathichemolyticanemia.

Althoughit may affectany organ, orthopedic and cerebral involvement is a relatively low and under-recognized feature of APS $[7,8]$.Our search yielded no reports concerning softtissue necrosis which required reconstruction in a case of APS. This patient had an unexpected evolution with improvements of tissue and skin gangren after highdose steroids. Our search for septic screen at admission to plastic surgery clinic was negative. There was no prolongation of PT and a PTT . Platelet counts at surgery time were normal and she was taking acetyl salicylic acid (100 mg/day). Under anti coagulant therapy there was no bleeding complication post operatively. So, this presentation highlights that reconstructive needs can occur in this group of patients as a complication of disease progress.

\section{References}

1. Peaceman AM, Silver RK, MacGregor SN, Socol ML (1992) Interlaboratory variation in antiphospholipid antibody testing. Am J Obstet Gynecol 166: 1780 1784.

2. Ehrenstein MR, Swana M, Keeling D, Asherson R, Hughes GR, et al. (1993) Anti-DNA antibodies in the primary antiphospholipid syndrome (PAPS). Br J Rheumatol 32: 362-365.

3. Vianna JL, Khamashta MA, Ordi-Ros J, Font J, Cervera R, et al. (1994) Comparison of the primary and secondary antiphospholipid syndrome: a European Multicenter Study of 114 patients. Am J Med 96: 3-9.

4. Gulko PS, Reveille JD, Koopman WJ, Burgard SL, Bartolucci AA, et al. (1993) Anticardiolipin antibodies in systemic lupus erythematosus: clinical correlates, HLA associations, and impact on survival. J Rheumatol 20: 1684-1693.

5. Ishii Y, Nagasawa K, Mayumi T, Niho Y (1990) Clinical importance of persistence of anticardiolipin antibodies in systemic lupus erythematosus. Ann Rheum Dis 49: 387- 390.

6. Cervera R, Bucciarelli S, Plasin MA, Gomez-Puerta JA, Plaza J, et al. (2009) Catastrophic antiphospholipid syndrome (CAPS): descriptive analysis of a series of 280 patients from the "CAPS Registry". J Autoimmun 32: 240-245.

7. Sanchez-Caballero FM, Marenco JL, Sanchez-Burson J, Rejon E, Aguilera JM, et al. (1999) Cerebral infarct in systemic lupus erythematosus. Rev Neurol 29: 985-990.

8. Piotrowksi M, Majdan M, Jablonski M, Gorzelak M (2007) Orthopedic complications of antiphospholipid syndrome: presentation of two cases. Pol Arch Med Wewn 117: 73-75. 